\title{
Periodontal Status of Smoker and Nonsmoker between the Workers at El kubaisa Factory of Cement \\ Mohammed I. Abdullah
}

B.D.S, M.Sc - Department of POP, College of Dentistry, University of Anbar

Shakir Mahmood Ali

B.D.S, M.Sc - Department of POP, College of Dentistry, University of Anbar

Jassim Ali Jassim

B.D.S, M.Sc - Department of oral medicine, College of Dentistry, University of Anbar

\begin{abstract}
Background:The harmful effect of smoking on oral tissues is well reported.The effects of smoking on periodontal health statues of a group of cement factory workers have been compared with the non smokers.

Methodology: A sample of 175 male subjects were involved 78(44.57\%) subject were smokers. Each subject was examined in the medical room in the factory. By using Community Periodontal Index (CPI) score.

Result: The prevalence of periodontal disease among the study subject was $100 \%$. Bleeding and calculus were most frequent observed in the smoker and non smoker workers with statistical difference $(\mathrm{P}>0.05)$. On the other hand the shallow $(74.35 \%)$ and deep pocket(23.08\%)were observed more in smokers. with significant differences $(P<0.01)$.

Conclusions: The maintaining of oral health was neglected by factory workers. Smoking was evidently factor of risk for high levels of periodontal disease. These observation emphasize the need of periodontal treatment in the cement factory workers.
\end{abstract}

KEYWORDS

Smokers, Community periodontal Index, periodontal health status

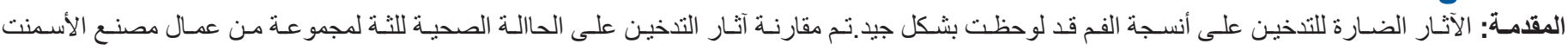

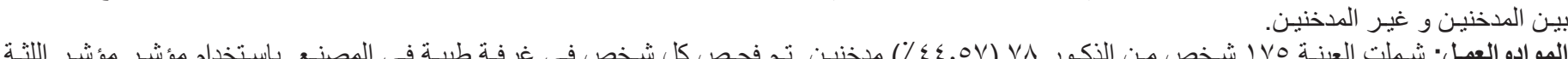

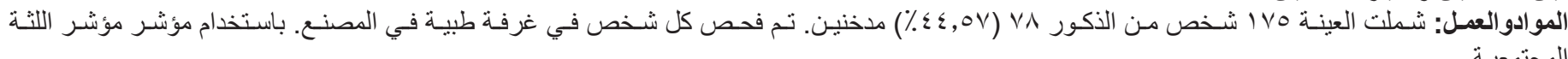

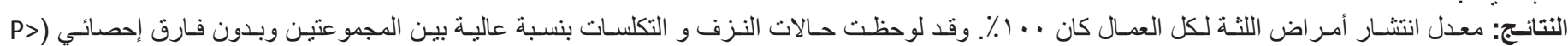

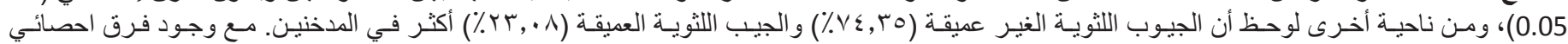

$$
\begin{aligned}
& \text { كبير (0.01)، ومن (P) ). }
\end{aligned}
$$

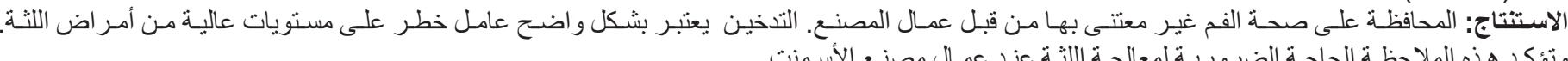

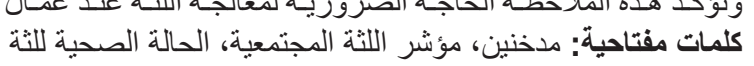

\section{INTRODUCTION}

The smoking and periodontal disease closely related and it is one of the most significant is a factor in the developing most of periodontal disease ${ }^{(1)}$. Smoking of cigarette is a factor of significant risk for disease of periodontal tissues ${ }^{(2)}$, that demonstrated by increasing the loss of the attachmen ${ }^{t(3,4,5)}$,developments and progressions of the inflammation of periodontal tissues ${ }^{(6,7)}$ and increasing the gingival recessions ${ }^{(8)}$. Several study was indicates that the nicotine which is found in products of tobacco triggers the over production of cytokines inside the body and this is due to lowered of the oxygen level. Cytokines are considered signal chemicals which is involved in the process of the inflammation of periodontal tissues. When the nicotine combined with the bacteria of oral cavity such as P.gingivalis, the effect will be higher level of cytokines, and it will lead to breakdown in the tissue that supporting the teeth ${ }^{(9)}$. Nicotine is considered the most pharmacologically active compound in tobacco smoker. Cigarette stimulate the sympathetic ganglia to produced neurotransmitter including catecholamine, these affect the alpha-receptor on blood vessels which in turns causes vasoconstriction. The peripheral blood vessels vasoconstriction that caused by smoking also affect the periodontal tissue ${ }^{(10)}$. In this study, the CPI index was used to estimate the effect of cigarette on the periodontal health. A prevalence was planned to assess the periodontal status of smoker and non smoker workers of cement factory.

\section{METHOD AND MATERIAL}

Cross sectional study was carried out on 175 (97 non smokers and 78 smokers) cement factory workers. Subjects who suffered from systemic disease and who were not willing to participate were excluded from the study. Prior to examination of each subject the workers interview to record information regarding to name, age, area of residency, smoker or no, expose to cement dust or no. Dental examination were carried out in supine position with artificial light in the medical room in the factory. The status of periodontal tissues was assessed by using Community Periodontal Index (CPI) and CPI probe which conform to World Health Organization $^{(11)}$ with disposable mouth mirrors were used. CPI was chosen because of simplicity, speed, international uniformity and records the common treatable conditions like periodontal pocket, gingival inflammation and calculus. This is an index records 
the worst case. Instruments used were sterilized using gluteraldehyde solution.

\section{Analysis of data}

The statistical analysis was conduct by using SPSS version 20 computer ( Statistical Package for Social Sciences) in the association with Excel version 5. Pearson's chi-square test was used to examine the differences between the different groups. So for all the test, P value of $<0.05$ was considered to be statistically significant. The magnitude of association between dichotomous independent variables (risk factor) and dichotomous outcome (dependent) variables was assessed by Odds ratio(OR). The confidence interval is $95 \%$ for OR is a statistical procedure to expect or predict the range expected of the possible values of the sample that calculated estimate of any statistic (like OR) in the population references with $95 \%$ confidence.

\begin{tabular}{l|c|ccc} 
& Positive & Negative & AD \\
\hline Positive & A & B & OR= \\
\hline Negative & C & D & $\frac{\mathrm{C}}{\mathrm{D}}$
\end{tabular}

\section{RESULTS}

A total number of 175 subjects were examined out of which $97(55.43 \%)$ were not smokers and $78(44.57 \%)$ which are smokers. The periodontal status of all workers illustrated in table (1). It obvious from this table that the shallow pocket among smoker and non smoker were $(74.35 \%, 68 \%)$ respectively. The differences between these two groups was statistically not significance $\mathrm{P}>0.05$. Whereas the deep pocket among smoker and non smoker were $(23.08 \%, 1 \%)$ respectively. The differences between these two groups was statistically highly significance $\mathrm{P}<0.001$. The percent of sextant effected by periodontal condition health among smoker and non smoker is illustrated in table (2). Which show no significant differences between smoker and non smoker in bleeding and calculus ( $\mathrm{P}>0.05$ ), but very high significant in shallow pocket $(\mathrm{P}<0.001$,OR 17.01, 95\% CPI OR 4.81-90.14) and very highly significant in deep pocket $(\mathrm{P}<0.001$, OR 28.8, 95\% CPI OR 5.06-287.33).

\section{DISCUSSIONS}

In this study an attempt was made to assess the periodontal health status using community periodontal index among the smokers and non smokers workers in EL-Kubaisa cement factory, Anbar governorate, Iraq. A group of the cement factory workers with a sample size of 175 with mean age(25-55 years) about(41.7 \pm 8.34$)$ were estimated for the use of tobacco of smoking and in the association with the levels of the destructions of the periodontal tissues . The smokers group were approximately $(78,44.57 \%)$ of the total workers which are examined, whereas non smokers group were approximately $(97,55.43 \%)$. In current study $0 \%$ of the subjects had healthy periodontium. Bleeding and calculus were widespread among smokers and non smokers. In the present study the shallow pockets $(4-5 \mathrm{~mm})$ among smokers were $(76,97.4 \%)$ while in non smokers were $(67,69.1 \%)$ Odd Ratio (OR) (17.01) 95\% CPI OR (4.81-90.14). Deep pockets (more than $6 \mathrm{~mm}$ ) among smokers were $(18,23.07 \%)$ while in non smoker were $(1,1 \%)$ OR (28.8) 95\% CPI OR (5.06-287.33). The severity of the disease was found to be relatively higher among smokers deep pocket (more than 6mm) was $(23.08 \%$ ). The our findings are approximately agreement with study conducted by Sood et al among the smoker in ceramic factory in Haryana, India. deep pocket(more than $6 \mathrm{~mm}$ ) was $(24.7 \%)^{(18)}$. Some of studies reported that the smoker people are more susceptible to the advanced and the severe forms of the periodontal disease than the people who are non smokers ${ }^{(12,15)}$. In a certain study that carried out to the periodontal tissue status among the male who are industrial workers in the Finland, it was found that the smoking of tobacco was the strongest independent factor affecting the status of the periodontal tissues ${ }^{(16)}$. Shizukuishi et al also it was observed in Japanese workers in a factory that the lifestyle which includes the smoking of tobacco and the insufficient of the oral health care have an independent association with the disease of the periodontal tissues ${ }^{(17)}$. This finding support the role of smoking as a risk factor for development and 
progression of periodontal disease. This has been by factory workers. Smoking was evidently factor of reported in the many previous studies ${ }^{(12,13)}$.

CONCLUSION risk for higher levels of the periodontal disease. These observation emphasize that periodontal treatment for

The maintaining of oral health was neglected these factory workers is needed.

Table(1): Prevalence of the periodontal health status among smokers and non smokers workers

\begin{tabular}{|c|c|c|c|c|c|}
\hline \multirow{2}{*}{ Maximum CPI Score } & \multicolumn{2}{c|}{$\begin{array}{c}\text { Smoker } \\
\boldsymbol{n}=\mathbf{8}\end{array}$} & \multicolumn{2}{c|}{$\begin{array}{c}\text { Nonsmoker } \\
\boldsymbol{n}=\mathbf{9 7}\end{array}$} & P (Chi-Square) \\
\cline { 2 - 6 } & No. & $\%$ & No. & $\%$ & \\
\hline Healthy & 0 & 0.0 & 0 & 0.0 & $*$ \\
\hline Bleeding & 0 & 0.0 & 1 & 1.0 & $0.36^{* *}$ \\
\hline Calculus & 2 & 2.56 & 29 & 29.9 & $<0.0001^{* * *}$ \\
\hline Shallow pocket 4-5 mm & 58 & 74.35 & 66 & 68 & $0.36^{*}$ \\
\hline Deep pocket $>6 \mathrm{~mm}$ & 18 & 23.08 & 1 & 1.0 & $<0.0001^{* * *}$ \\
\hline Total & 78 & 100 & 97 & 100 & \\
\hline
\end{tabular}

*cannot calculated $\quad * *$ No Significant $\mathbf{P}>\mathbf{0 . 0 5} \quad * * *$ very high Significant $\mathbf{P}<0.0001 \mathrm{df}=1$

Table(2): Percent of Sextant affected by periodontal condition among smokers and non smokers workers

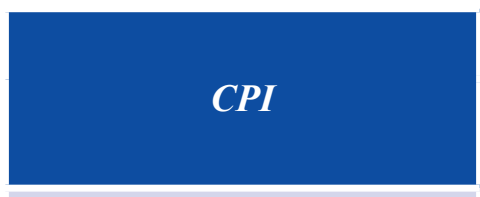

\begin{tabular}{|c|c|}
\hline Smoker $\boldsymbol{n}=78$ \\
\hline No. & $\%$ \\
\hline
\end{tabular}

Bleeding or higher

Calculus or higher

Shallow pocket Or higher

Deep pocket Or higher

$18 \quad 23.07$

\begin{tabular}{|c|c|}
\hline Non smoker $\boldsymbol{n}=97$ \\
\hline No. & $\%$ \\
\hline
\end{tabular}

\begin{tabular}{|c|}
\hline 100 \\
\hline 99 \\
\hline 69.1 \\
\hline 1.0 \\
\hline
\end{tabular}

1

1.0
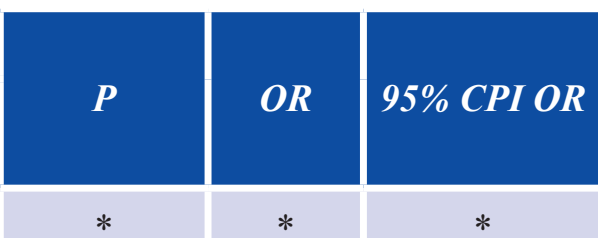

*

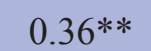

$0.001 * * *$

0.001

(4.81-90.14)

28.8

(5.06-287.33)

$*$ can not calculated $* *$ No Significant $\mathbf{P}>0.05 * * *$ Very Highly Significant $\mathbf{P}<0.001$ df $=1$ OR(odd ratio)

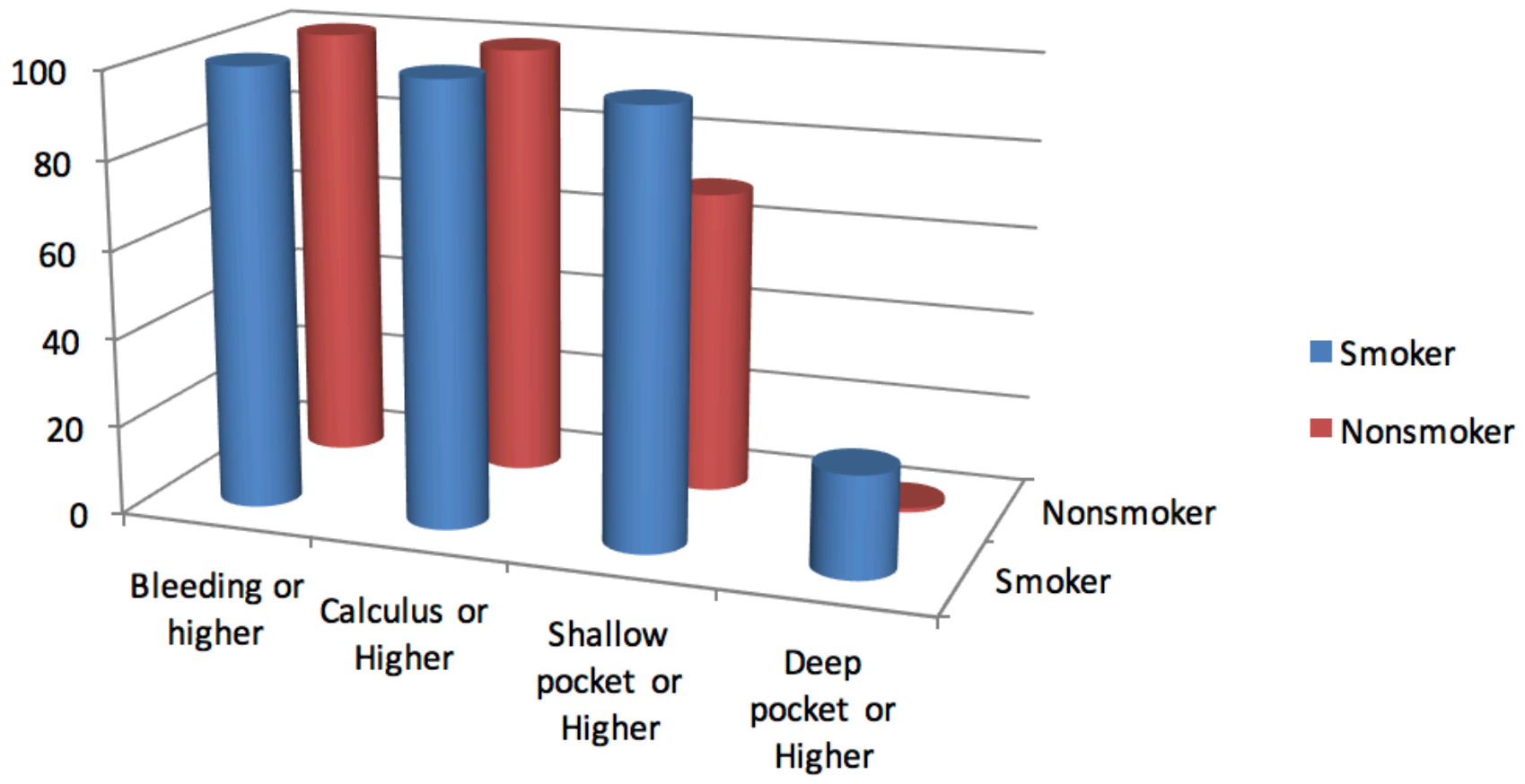

Figure: Percent of Sextant affected by periodontal condition among smokers and non smokers 


\section{REFERENCES}

1. Sakthi S, John J, Saravanan S, Pradeep R. Periodontal health status and treatment need among building construction workers in Chennai, India. J Int Oral Health 2011; 3(6): 7-14.

2. Tanner A, Kent R, Van Dyke T, Sonis S and Murray L. Clinical and other Risk Indicators for Early Periodontitis in Adults. J periodontal. 2005; Vol. 76:573-81.

3. Hyman $J$ and Reid B. Epidemiological Risk factors for periodontal Loss among Adult in the united states. J Clin periodontal. 2003;30:230-237.

4. Amarasena N, Ekanayaka A, Herath L and Miyazaki H. Tobacco use and oral hygiene as Risk Indicators for periodontitis. Community Dent Oral Epidemiol.2003;Vol.31:158-160.

5. Razali M, Palmer R, Coward P and Wilson R. Retrospective study of Periodontal Disease Severity in Smokers and Non smokers. British Dent Journal .2005;198:495-498.

6. James J, Sayers N, Drucker D and Hul I. Effect of Tobacco products on the Attachment and Growth of periodontal Ligament Fibroblast. J Periodontal. 1999;70:518-525.

7. Genco R, Current View of Risk Factors for periodontal disease. J Periodontal.1996;67:1041-1049.

8. Muller H, Stadermann $\mathrm{S}$ and Heinecke A. Gingival Reecession in Smokers and Non smokers with Minimal Periodontal Disease. J Clin Periodontal.2002;29:129-136.

9. Marget J, Risk factors for periodontal disease. The Richmond institute for continuing Dental education.2007;6(2):1-4.

10. Pejcic A, Zivkovic V. Histological Examination of Gingiva Treated with Low level Laser in Periodontal therapy. J Oral Laser.2007; 7:37-43.

11. World Health Organization. Oral health surveys: basic methods. 4th ed. Geneva: ORH/EPID; 1997.

12. Haber J, Wattles J, Crowley M, Mandell R, Joshipura K and Kent R. Evidence for Cigarette smoking as a major risk factor for periodontitis. J Periodontal 1993;64:16-2

13. Salvi G, Ramseier C, Sigrist L, Awedowa E and Lang N. Experimental gingivitis in cigarette smokers. A clinical and microbiological study. J Clin Periodontal 2005;32:441-47.

14. Bozkurt F, Ay Z, Sutcu R, Delibas N and Demirel R. Gingival crevicular fluid leptin levels in periodontitis patients with long-term and heavy smoking . J Periodontol.2006;77(4):634-40.

15. Calsina G, Ramon J and Echevernia J. Effects of smoking on periodontal tissues. J Clin Periodontol 2002;29:771-76.

16. Ahlberg J, Tuominen $\mathrm{R}$ and Murtomaa H. Periodontal status among male industrial workers in Southern Finland with or without access to subsidized dental care. Acta Odontologica Scandinavica 1996;54(3):166-70.

17. Shizukuishi S, Hayashi N, Tamagawa H, Hanioka $T$, Maruyama S, Takeshita T. Life style and periodontal health status of Japanese Factory workers. Ann Periodontol.1998; 3: 303-11.

18. Sood M, Blaggana A, Vohra P, Saraf B. Periodontal status of smoker and non smoker Ceramic Factory Workers. J ID, 20111;(3):1-7

\section{Case sheet}

Name:

Age

Area of residency:

Medical history :

Yes

No

Hypertension

Diabetic

Asthma

Others

Smoker habit

Expose to cement dust

Yes

No

Yes

No

CPI
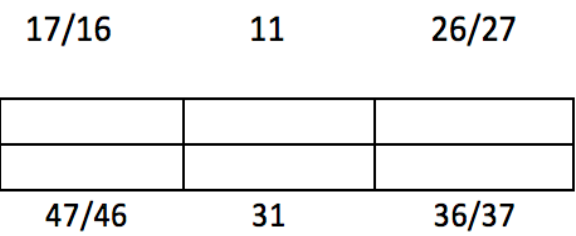